\title{
Minimal access versus open spinal surgery in treating painful spine metastasis: a systematic review
}

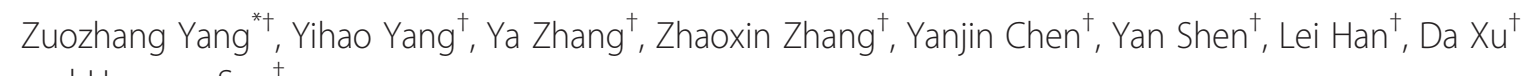
and Hongpu Sun ${ }^{\dagger}$

\begin{abstract}
Study design: The study design of this paper is a systematic review of literature published in the recent 10 years. Objective: It is the objective of this paper to compare the clinical efficacy and safety of minimal access (MIS) spinal surgery and open spinal surgery for treating painful spine metastasis.

Methods: Two research questions below were determined through a consensus among a panel of spine experts. A systematic review of literature on spinal surgery was conducted by searching PubMed with a combination of keywords including "metastatic", "metastasis", "metastases", "spinal", and "spine". Independent reviewers selected the articles for analysis after screening the titles, abstracts, and full texts, then extracted data and graded the quality of each paper according to the Grading of Recommendations, Assessment, Development, and Evaluation (GRADE) criteria. Specific clinical questions were as follows:
\end{abstract}

1. In patients with spine metastatic disease, what is the impact of different surgical approaches (MIS versus open) on pain relief and functional outcome?

2. In patients with metastatic disease, what is the impact of different surgical approaches (MIS versus open) on local recurrence, survive rate, and complication?

Results: A total of 1,076 abstracts were identified using various keywords. 5 prospective (level II) and 12 retrospective articles (level III) were eligible for inclusion, involving a total of 979 cases of spine metastasis. There were 345 cases in 8 studies regarding the clinical evaluation of MIS spinal surgery and 634 cases in 9 studies regarding the clinical evaluation of open spinal surgery for spine metastasis.

Conclusion: Both open spinal surgery and MIS seem to achieve the improvement of pain and neurological dysfunction through decompression and stabilization for patients with spine metastasis, but open surgery may involve more major complications with a trend of lower survival rates and higher recurrence rates compared to MIS.

Keywords: Minimal access, Open spinal surgery, Spine metastasis, Systematic review

\footnotetext{
* Correspondence: yangzuozhangpre@163.com

${ }^{\dagger}$ Equal contributors

Bone and Soft Tissue Tumors Research Center of Yunnan Province, the Third Affiliated Hospital of Kunming Medical University (Tumor Hospital of Yunnan Province), Kunming, Yunnan 650118, PR China
} 


\section{Review}

Introduction

About $10 \%$ of cancer patients develop metastases in the spine [1]. The most common site of metastasis in the spine is the thoracic spine $(50 \%$ to $60 \%$ of all metastases), followed by the lumbar (30\% to $35 \%)$ and cervical spines (10\% to $15 \%)$ [2-4]. Vertebral metastasis is one of the most serious life-threatening diseases [5]. About one third of patients with spinal metastases become symptomatic, which means intractable pain, neurological deficits, and/or biomechanical instability requiring surgical treatment $[3,6]$.

These nonsurgical methods, such as chemotherapy, radiotherapy, and hormonal therapy, were commonly used for the management of vertebral metastatic disease, which have been proven to be effective in halting the osteolytic process and reversing the neurological compromise [7]. However, these modalities are unable to provide stability to an instable spinal column and also unable to be expected to relieve pain and spinal cord compression. In these cases, surgery is the best method for the resolution of intractable pain, neurological compromise, and overt or impending spinal instability in patients with spinal metastases. The primary goal of the surgery is to improve patients' quality of life by providing pain relief, maintaining or improving neurological function, and restoring the structural integrity of the spinal column [8].

Stabilization of the spine is often necessary as extensive lesions may cause spinal instability by erosion of the normal bony structures. The most efficacious therapy for restoring spinal instability is reconstructive surgical intervention. Unfortunately, lots of patients are not considered as candidates for conventional surgery intervention due to neoplasm-associated comorbidities such as malnourishment and a weak immune system that make amounts of surgical procedures unfeasible [9]. However, these patients can be managed with vertebral augmentation, since it can provide some degree of restabilization [10].

Vertebroplasty or kyphoplasty, which involves the percutaneous injection of polymethyl methacrylate (PMMA) bone cement into a collapsed vertebral body, is a currently available minimally invasive spine surgery for palliative treatment. Poor surgical candidates with disabling pain secondary to a pathologic thoracic or lumbar vertebral body fracture without epidural compression are ideal candidates for these procedures [11]. The two procedures have been shown to relieve pain effectively to improve the quality of life, and they can be used as effective palliative treatment even for patients whose general condition is quite poor, with decreased pain, less blood loss, and shorter hospital stays [12]. On the other hand, their putative benefits with regard to spinal stability and neurological function, as well as their risks affecting their overall survival, have not yet been adequately documented by clinical studies because of limitations such as insufficient spinal cord decompression and stabilizing the vertebral column.

Despite numerous reports on open spinal surgery in treating painful spine metastasis, there exist no randomized controlled comparisons of clinical efficacy and safety between open and minimal access (MIS) procedures. In addition, due to the heterogeneity of study designs, inconsistent reporting of complications, and the use of different grading scales for pain and functional outcomes, it was not possible to perform a meta-analysis using the prospective and retrospective studies. Therefore, we endeavored to perform a quantitative systematic review of the current literature published in the recent 10 years to evaluate the clinical efficacy between MIS and open spinal surgery in patients with spinal metastases. A secondary aim was to compare complication rates between MIS and open spinal surgery.

\section{Materials and methods}

Two clinically relevant questions below were determined through a consensus among a panel of spine oncology experts (the Spine Oncology Study Group), and a systematic review of related literature published in the recent 10 years was conducted using PubMed. Specific clinical questions were as follows:

1. In patients with metastatic disease, what is the impact of different surgical approaches (MIS versus open) on alterations of pain and neurologic function?

2. In patients with metastatic disease, what is the impact of different surgical approaches (MIS versus open) on local recurrence, survive rate, and complication?

\section{Search criteria}

We used the search terms that included "spin*", "metasta", and "surg*" to searched literature from PubMed. The following terms would be contained: "metastatic", "metastasis", "metastases", "spinal”, "spine”, "surgery", and "surgical".

Criteria for possible inclusion are as follows: 1) articles published in the recent 10 years, 2) all articles in English or with an English translation, 3) articles with 20 or more subjects, 4 ) adult age group (18 years and older), 5) articles describing surgical treatment of spinal metastatic cancer, and 6) articles evaluating the alterations of pain and neurologic function postoperatively. Exclusion criteria include the following: 1) primary tumors, 2) intradural tumors, 3) pediatric age group, 4) articles with fewer than 20 subjects, and 5) articles with 
nonhomogeneous pathology (e.g., trauma and primary tumors in the same series).

Studies were reviewed using a standardized data collection form. The type of study (prospective or retrospective) was noted. Data including surgery technique, the total number of patients, and the type of tumors were totally collected. The methods of pre- and postoperative clinical evaluations with respect to pain and functional outcome were also recorded. All temporary and permanent complications were collected, including major and minor complications. To avoid duplicate records of patients' data, each group or institution was limited to one study in the systematic review. Some authors were contacted directly to clarify certain aspects of their studies.

The quality of evidence for each article was evaluated as high, moderate, low, or very low. The results of the systematic review and ratings of the evidence for each article were determined by a multidisciplinary, international group of spine oncology surgeons, oncologists, and methodologists (Spine Oncology Study Group). The group then went through a consensus-based decisionmaking process using a modified Delphi technique to arrive at treatment recommendations related to the key clinical questions. This process and the strength of the recommendation were based on the Grading of Recommendations, Assessment, Development, and Evaluation (GRADE) method [13,14]. These articles were evaluated independently by the authors according to the GRADE criteria.

\section{Result}

A total of 1,076 abstracts were identified using various keywords. All abstracts were screened, and 1,013 articles were excluded as obviously unrelated. The full texts of 63 papers were screened and 17 papers were identified to meet the inclusion criteria, including 5 prospective (level II) [15-19] and 12 retrospective articles (level III) [20-31] involving 979 cases of spine metastasis. The details of article selection were presented in Figure 1. There were 345 cases in 8 studies regarding the clinical evaluation of MIS spinal surgery and 634 cases in 9 studies regarding the clinical evaluation of open spinal surgery for spine metastasis (Table 1). In one study, the primary cancer was breast cancer, whereas in other studies were a mixed group such as lung cancer, prostate cancer, and colon cancer.

Among these articles regarding open spinal surgery, three studies were performed with several kinds of approaches such as posterior, anterior, and combined approach

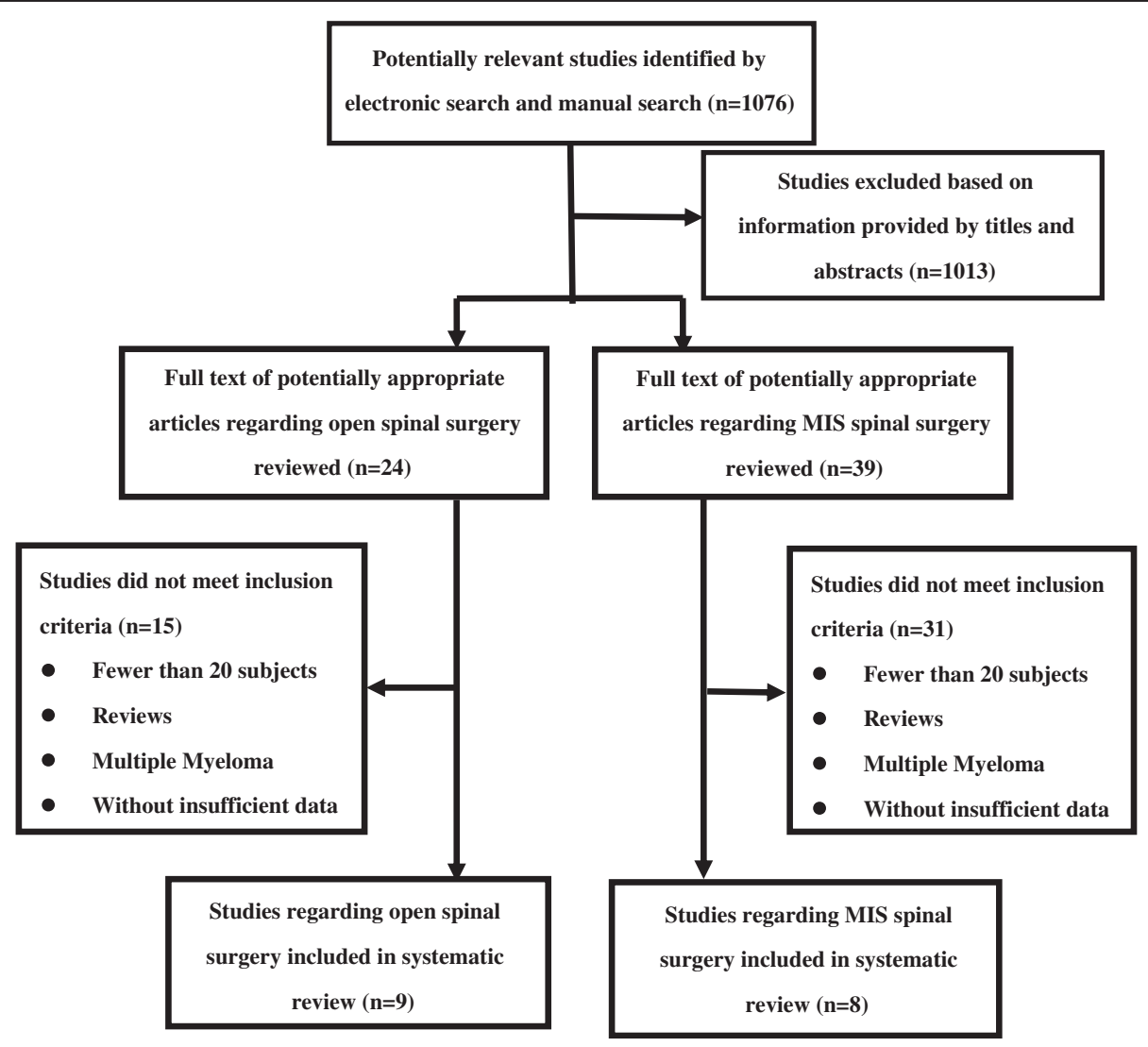

Figure 1 Flow diagram showing identification of studies included in the review. 
Table 1 Characteristics of included studies

\begin{tabular}{|c|c|c|c|c|c|c|c|c|c|}
\hline Study & Year & Type of study & Quality & $\begin{array}{l}\text { Number of } \\
\text { Patients }\end{array}$ & Mean age & Procedure & Primary & Outcome & Follow-up \\
\hline \multicolumn{10}{|l|}{ Minimal } \\
\hline Pizzoli et al. [20] & 2009 & Retrospective & Very low & 39 & NA & PVP with PMMA & Mixed & VAS, mobility, analgesic use & NA \\
\hline Chen et al. [21] & 2009 & Retrospective & Very low & 31 & 67 & PVP with PMMA & Mixed & VAS, Karnofsky scale & 12 months \\
\hline Qian et al. [22] & 2011 & Retrospective & Very low & 48 & 68.5 & Kyphoplasty & Mixed & $\begin{array}{l}\text { VAS, ODI, SF-36, vertebral body } \\
\text { height variation }\end{array}$ & 24 months \\
\hline Farrokhi et al. [15] & 2012 & Prospective & Very low & 25 & 53.5 & PVP with PMMA & Mixed & VAS & NA \\
\hline Tseng et al. [23] & 2008 & Retrospective & Very low & 57 & 65.18 & PVP with PMMA & Mixed & $\begin{array}{l}\text { VAS, amounts of nonnarcotic } \\
\text { and narcotic analgesic }\end{array}$ & 6 months \\
\hline Yang et al. [16] & 2009 & Prospective & Very low & 40 & 57.63 & PVP with PMMA & Mixed & VAS, KPS & 1 year \\
\hline Pflugmacher et al. [17] & 2008 & Prospective & Very low & 65 & 66 & Balloon kyphoplasty & Mixed & VAS, ODI & 24 months \\
\hline Anselmetti et al. [18] & 2013 & Prospective & Very low & 40 & 66.8 & PVP with PEEK & Mixed & VAS, ODI & 10 months \\
\hline \multicolumn{10}{|l|}{ Open } \\
\hline Holman et al. [24] & 2005 & Retrospective & Very low & 139 & 55 & $\begin{array}{l}\text { Posterior/anterior/combined tumor resection, } \\
\text { decompression, instrumentation, fusion }\end{array}$ & Mixed & VAS, Frankel grades & 12 months \\
\hline Chong et al. [25] & 2012 & Retrospective & Very low & 105 & 58.3 & $\begin{array}{l}\text { Single-stage posterior decompression } \\
\text { and stabilization }\end{array}$ & Mixed & VAS, Frankel grade, KPS & 48 months \\
\hline Eid et al. [26] & 2011 & Retrospective & Very low & 45 & 53 & $\begin{array}{l}\text { Circumferential decompression and fusion } \\
\text { by means of PTA }\end{array}$ & Mixed & VAS, ASIA grades & 13 months \\
\hline Liang et al. [27] & 2013 & Retrospective & Very low & 92 & NA & $\begin{array}{l}\text { Posterior/anterior/combined tumor resection, } \\
\text { decompression, instrumentation, fusion }\end{array}$ & Mixed & $\begin{array}{l}\text { VAS, Frankel grades, Karnofsky } \\
\text { score, Tokuhashi scores }\end{array}$ & 22 months \\
\hline Wonik Cho et al. [28] & 2012 & Retrospective & Very low & 46 & 56.4 & $A C F, A C F$ and $P F, D L F, D L$ & Mixed & VAS, JOAS, Tomita score & 39 months \\
\hline Walter et al. [29] & 2012 & Retrospective & Very low & 57 & 58.6 & $\begin{array}{l}\text { Posterolateral approach for decompression } \\
\text { combined with posterior instrumentation }\end{array}$ & Mixed & $\begin{array}{l}\text { VAS, Frankel grades, ECOG } \\
\text { grades, TPS }\end{array}$ & 46 months \\
\hline Dae-Chul Cho et al. [30] & 2009 & Retrospective & Very low & 21 & 56.6 & $\begin{array}{l}\text { Posterolateral transpedicular approach with } \\
\text { posterior instrumentation }\end{array}$ & Mixed & $\begin{array}{l}\text { VAS, Frankel grades, and } \\
\text { ECOG grades }\end{array}$ & 13 months \\
\hline Shehadi et al. [31] & 2007 & Retrospective & Very low & 87 & 53 & $\begin{array}{l}\text { Posterior/anterior/combined tumor resection, } \\
\text { decompression, instrumentation, fusion }\end{array}$ & Breast cancer & VAS, Frankel grades & 13 months \\
\hline Street et al. [19] & 2007 & Prospective & Very low & 42 & 56.04 & Single-stage posterolateral vertebrectomy & Mixed & VAS, ECOG grading & NA \\
\hline
\end{tabular}

PVP percutaneous vertebroplasty, PMMA polymethyl methacrylate, PEEK polyetheretherketone, VAS visual analog scale, ODI Oswestry Disability Index, JOAS Japanese Orthopaedic Association Score, KPS Karnofsky

performance scores, ASIA American Spinal Injury Association, ECOG Eastern Cooperative Oncology Group, PTA posterolateral transpedicular approach, TPS Tomita's prognostic score, ACF anterior corpectomy and fusion, ACF and PF ACF and posterior fixation, DLF decompressive laminectomy posterior fixation, DL decompressive laminectomy, NA not available, SF-36 Short Form 36 Physical Function. 
to remove tumors in spines. Studies regarding MIS spinal surgery were performed primarily with vertebroplasty whereas two studies $[22,17]$ were performed with kyphoplasty.

Pain alleviation was crucially important for the therapy of spine metastases to improve quality of life in patients. A visual analog scale was available for each study to evaluate the effect of pain relief in patients with spine metastases. In all, one study did not display the visual analog scale (VAS) score in detail [26], and prospective studies had especially detailed pre- and postoperative VAS score. It was found that both MIS and open spinal surgery were efficient in pain alleviation, and most of the studies reported statistically significant improvement (Table 2).Given the high rates of pain alleviation, the results suggest that both MIS and open spinal surgery are efficacious in respect to pain alleviation through decompression and stabilization.

Each study assessed postoperative neurologic function, and multiple methods for evaluating neurologic function were included, such as the Eastern Cooperative Oncology Group performance scale, the Oswestry Disability Index, the Frankel scale, the Karnofsky scale and American Spinal Injury Association grades, the Short Form 36
Physical Function, the Japanese Orthopaedic Association Score, and the Karnofsky performance scores. The neurologic function was not assessed in two studies (Farrokhi et al. [15] and Tseng et al. [23]) regarding MIS surgery. Only nine studies provided pre- and postoperative neurologic function score, and neurologic function was statistically significantly improved (Table 3 ). Other studies without detailed data also showed that MIS and open spinal surgery were successful in improving physical function.

It is reported that decreased complication rates are considered to be one of the advantages of MIS spinal surgery. This was confirmed by the evidences we provided in this systematic review. There are no major complications for MIS spinal surgery except in two studies $[20,23]$, whereas six studies regarding open spinal surgery reported major complications with a trend of lower survive rates and higher recurrence rates (Table 4).

\section{Discussion}

For most of the patients with spinal metastasis, the treatment is largely palliative and aims to achieve relief of pain and regain function, thus improving the quality of the life of the patients. Because of the immunocompromised

Table 2 VAS scores in included studies

\begin{tabular}{|c|c|c|c|c|c|}
\hline Study & Pre & Post & $P$ value & Follow-up & Pain relief rate \\
\hline \multicolumn{6}{|l|}{ Minimal } \\
\hline Pizzoli et al. [20] & $8.62( \pm 0.71)$ & $2.84( \pm 1.36)$ & NA & $24 \mathrm{~h}$ & $98 \%$ \\
\hline Chen et al. [21] & $8.9( \pm 0.93)$ & $2.6( \pm 1.71)$ & $P<0.001$ & NA & $94 \%$ \\
\hline \multirow[t]{2}{*}{ Qian et al. [22] } & $7.4( \pm 2.1)$ & $3.8( \pm 1.6)$ & $P<0.001$ & $24 \mathrm{~h}$ & NA \\
\hline & & $3.2( \pm 1.0)$ & $P<0.001$ & 6 months & NA \\
\hline \multirow[t]{2}{*}{ Farrokhi et al. [15] } & $8.23(\mathrm{NA})$ & $2.12(N A)$ & $P \leq 0.05$ & $24 \mathrm{~h}$ & NA \\
\hline & & 1 (NA) & $P \leq 0.05$ & 2 months & NA \\
\hline \multirow[t]{2}{*}{ Tseng et al. [23] } & $8.1( \pm 0.67)$ & $3.8( \pm 1.9)$ & $P<0.015$ & $24 \mathrm{~h}$ & NA \\
\hline & & $2.8( \pm 2.0)$ & $P<0.001$ & 6 months & NA \\
\hline Yang et al. [16] & $8.78( \pm 0.54)$ & $5.41( \pm 0.94)$ & $P=0.032$ & 6 months & $95.00 \%$ \\
\hline Pflugmacher et al. [17] & $8.3( \pm 15)$ & $3.3( \pm 9)$ & $P<0.0001$ & 3 months & NA \\
\hline Anselmetti et al. [18] & $10( \pm 1)$ & $1( \pm 0.75)$ & $P<0.001$ & 1 month & $100.00 \%$ \\
\hline \multicolumn{6}{|l|}{ Open } \\
\hline Holman et al. [24] & 7 (NA) & $2(N A)$ & $P<0.001$ & 1 month & $94 \%$ \\
\hline Chong et al. [25] & $6.5( \pm 1.7)$ & $3.4( \pm 1.6)$ & NA & 2 weeks & NA \\
\hline Eid et al. [26] & NA & NA & NA & 1 month & $96 \%$ \\
\hline Liang et al. [27] & $6(\mathrm{NA})$ & $2(N A)$ & $P<0.001$ & 12 months & $90 \%$ \\
\hline Wonik Cho et al. [28] & $7.86( \pm 1.05)$ & $4.48( \pm 2.09)$ & $P=0.001$ & NA & NA \\
\hline Walter et al. [29] & $6.9( \pm 1.6)$ & $3.1( \pm 1.0)$ & $P<0.001$ & 1 month & $87.70 \%$ \\
\hline Dae-Chul Cho et al. [30] & $6.82( \pm 2.13)$ & $3.61( \pm 1.01)$ & NA & 1 month & NA \\
\hline Shehadi et al. [31] & $6(\mathrm{NA})$ & $2(N A)$ & $P<0.001$ & 1 month & NA \\
\hline Street et al. [19] & 7.94 (NA) & $4.3(\mathrm{NA})$ & $P<0.001$ & NA & NA \\
\hline
\end{tabular}


Table 3 Neurologic function evaluation in included studies

\begin{tabular}{|c|c|c|c|c|}
\hline Study & Method & Scale best to worst & Functional outcome & $P$ value \\
\hline \multicolumn{5}{|l|}{ Minimal } \\
\hline Pizzoli et al. [20] & Mobility & 1 to 4 & Preoperative: $3.25 \pm 0.59$, postoperative: $1.24 \pm 0.64$ & $P<0.001$ \\
\hline Chen et al. [21] & Karnofsky scale & 100 to 0 & Preoperative: $50 \pm 10.65$, postoperative: $70 \pm 3.59$ & NA \\
\hline \multirow[t]{2}{*}{ Qian et al. [22] } & ODI & 0 to 100 & Preoperative: $71.5 \pm 16.7$, postoperative: $29.5 \pm 10.2$ & $P<0.001$ \\
\hline & SF-36 & 100 to 0 & Preoperative: $34.3 \pm 10.8$, postoperative: $54.5 \pm 10.5$ & $P<0.05$ \\
\hline Yang et al. [16] & Karnofsky scale & 100 to 0 & Preoperative: $69.4 \pm 8.3$, postoperative: $80.3 \pm 7.2$ & $P=0.002$ \\
\hline Pflugmacher et al. [17] & ODI & 0 to 100 & Preoperative: $81 \pm 8$, postoperative: $39 \pm 7$ & $P<0.0001$ \\
\hline Anselmetti et al. [18] & ODI & 0 to 100 & Preoperative: 82.2, postoperative: 4.1 & $P<0.001$ \\
\hline \multicolumn{5}{|l|}{ Open } \\
\hline Holman et al. [24] & Frankel grade & E to $A$ & $\begin{array}{l}\text { 46/112 (41\%) improved at least one Frankel grade, 20/112 } \\
(18 \%) \text { regained ambulation, seven (5\%) worsened }\end{array}$ & $P<0.05$ \\
\hline Chong et al. [25] & Frankel grade & E to $A$ & $\begin{array}{l}21 / 105(20 \%) \text { improved at least one Frankel grade, 21/105 } \\
(48 \%) \text { regained ambulation, } 6 / 105(5.7 \%) \text { worsened }\end{array}$ & $P<0.05$ \\
\hline Eid et al. [26] & ASIA grade & E to $A$ & $\begin{array}{l}23 / 45(51 \%) \text { improved one or more grades, } 6 / 45(20 \%) \\
\text { retained their preoperative grade, one (3\%) experienced } \\
\text { worsening }\end{array}$ & $P>0.05$ \\
\hline \multirow[t]{2}{*}{ Liang et al. [27] } & Karnofsky scores & 100 to 0 & $\begin{array}{l}\text { The median postoperative Karnofsky scores increased } \\
\text { from } 60 \text { (range, } 40 \text { to } 80 \text { ) to } 70 \text { (range, } 0 \text { to } 80 \text { ) }\end{array}$ & $P<0.001$ \\
\hline & Frankel grade & E to $A$ & $78 \%$ improved 1.2 grades at average & NA \\
\hline Wonik Cho et al. [28] & JOAS & 10 to 0 & Preoperative: $13.11 \pm 2.75$, postoperative: $15.17 \pm 2.09$ & $P=0.001$ \\
\hline \multirow[t]{2}{*}{ Walter et al. [29] } & Frankel grade & E to $A$ & $\begin{array}{l}13(22.8 \%) \text { patients improved, } 43(75.5 \%) \text { had a stable } \\
\text { neurological status, one single patient (1.8\%) experienced } \\
\text { worsening }\end{array}$ & NA \\
\hline & ECOG grade & 0 to 5 & Preoperative: $2.0 \pm 1.1$, postoperative: $1.7 \pm 1.3$ & $P<0.05$ \\
\hline \multirow[t]{2}{*}{ Dae-Chul Cho et al. [30] } & Frankel grade & E to $A$ & $\begin{array}{l}\text { 7/22 (33.3\%) improved, 14/21 (66.7\%) had a stable } \\
\text { neurological status }\end{array}$ & NA \\
\hline & ECOG grade & 0 to 5 & $\begin{array}{l}8 \text { had an improved ECOG grade, and } 12 \text { showed no change, } \\
1 \text { experienced worsening }\end{array}$ & NA \\
\hline Shehadi et al. [31] & Frankel grade & E to $A$ & $85 \%$ maintained or improved their Frankel scores & NA \\
\hline Street et al. [19] & ECOG grade & 0 to 5 & Preoperative: $2.5 \pm 1.0$, postoperative: $1.6 \pm 0.75$ & NA \\
\hline
\end{tabular}

ODI Oswestry Disability Index, Japanese Orthopaedic Association Score, ECOG Eastern Cooperative Oncology Group, NA not available, SF-36 Short Form 36 Physical Function.

status, poor nutrition, and comorbid medical conditions, many patients with spinal metastasis cannot tolerate the curative surgical methods. In recent years, more and more minimally invasive spinal interventions are reasonable alternatives to open spinal surgery for treating spinal metastatic tumors. These procedures can contribute to less soft tissue trauma, lower blood loss, and shorter hospitalization time. MIS spinal surgery rarely interferes with the adjuvant treatments. The overall morbidity is considerably lower in comparison to conventional spine surgery.

Despite this evolution, questions surrounding the effectiveness of MIS and its comparability to open spinal surgery in terms of pain and neurologic function remain unanswered. A direct comparison of clinical efficiency and safety between open and MIS spinal surgery for spinal metastasis has never been conducted. Given the lack of comparison studies, we aimed to compare the effect of pain alleviation and functional improvement between open and MIS spinal surgery by reviewing published studies in a quantitative manner. Our results suggest that open or MIS spinal surgery is likely to achieve the improvement in pain and neurological dysfunction for spinal metastasis, but open surgery seems to involve more major complications with a trend of lower survival rates and higher recurrence rates compared to MIS surgery.

There are few comparison studies between MIS and open spinal surgery. Huang et al. [32] performed a direct retrospective comparison of MOT, MBL, LOS, and CR for MIS versus open spinal surgery for thoracic spine metastasis, and no significant difference was found. However, the amount of patients requiring at least a 2-day admission in the open group was significantly larger than 
Table 4 Serious complications in included studies (excluding deaths)

\begin{tabular}{|c|c|c|c|}
\hline Study & Recurrence & Survival & Complications \\
\hline \multicolumn{4}{|l|}{ Minimal } \\
\hline Pizzoli et al. [20] & $5.1 \%$ & NA & $\begin{array}{l}\text { Three major complications (one pneumothorax and } \\
\text { two symptomatic leakages) }(2.8 \%) \text {, two minor } \\
\text { complications (cement pulmonary embolism) }(1.8 \%)\end{array}$ \\
\hline Chen et al. [21] & NA & $74 \%$ at 6 months, $39 \%$ at 12 months & No major complication \\
\hline Qian et al. [22] & No & $81 \%$ at 2 years & No major complications, cement leakage (18.6\%) \\
\hline Farrokhi et al. [15] & NA & NA & Cement leakage (44\%) \\
\hline Tseng et al. [23] & NA & Two patients died during hospitalization & $\begin{array}{l}\text { Cement extravasation ( } 17.9 \% \text { minor extravasation, } \\
3.9 \% \text { major extravasation)(21.8\%) }\end{array}$ \\
\hline Yang et al. [16] & No & $80.0 \%$ at 1 year & Seven paravertebral cement leakage (17.5\%) \\
\hline Pflugmacher et al. [17] & & $80.0 \%$ at 1 year, $66 \%$ at 2 years & $\begin{array}{l}\text { Cement leakage }(12.1 \%) \text {, adjacent incident } \\
\text { fracture }(8 \%)\end{array}$ \\
\hline Anselmetti et al. [18] & $20 \%$ & $85 \%$ at 3 months & Cement leakage (16.3\%) \\
\hline \multicolumn{4}{|l|}{ Open } \\
\hline Holman et al. [24] & $8 \%$ & $\begin{array}{l}\text { Mean survival was } 14.8 \text { months, } 67 \% \text { at } \\
0.5 \text { months, } 54 \% \text { at } 1 \text { month, } 23 \% \text { at } 5 \text { years }\end{array}$ & $\begin{array}{l}\text { Major complications (18\%) and minor } \\
\text { complications (21\%) }\end{array}$ \\
\hline Chong et al. [25] & NA & $\begin{array}{l}\text { Median survival was } 6.0 \text { months, } 34 \% \text { at } \\
1 \text { year, } 14 \% \text { at } 2 \text { years survival rates }\end{array}$ & $\begin{array}{l}\text { Surgical complications occurred in patients (10\%), } \\
\text { no mechanical failure }\end{array}$ \\
\hline Eid et al. [26] & No & Mean survival was 13 months & $\begin{array}{l}\text { Unstable (15.5\%), wound infection }(15.5 \%) \text {, } \\
\text { hematoma (4\%) and deep vein thrombosis (2\%) }\end{array}$ \\
\hline Liang et al. [27] & NA & $\begin{array}{l}\text { The median survival was } 15 \text { months, } 61 \% \text { at } \\
1 \text { year, and } 35 \% \text { at } 3 \text { years }\end{array}$ & Major complications (23\%) \\
\hline Wonik Cho et al. [28] & $39.10 \%$ & $\begin{array}{l}\text { Mean survival was } 11.82 \text { months, } 44.4 \% \text { at } \\
6 \text { months, } 35.6 \% \text { at } 12 \text { months, and } 19.0 \% \text { at } \\
24 \text { months }\end{array}$ & $\begin{array}{l}\text { Two operation site infection, two pneumonia, one } \\
\text { esophageal fistula after anterior approach (10.9\%) }\end{array}$ \\
\hline Walter et al. [29] & $1.70 \%$ & $\begin{array}{l}\text { Mean survival was } 11.4 \text { months, } 42.1 \% \text { at } \\
1 \text { year }\end{array}$ & Superficial wound infections and one seroma (5.3\%) \\
\hline Dae-Chul Cho et al. [30] & $14 \%$ & Mean survival was 8.9 months & $\begin{array}{l}\text { One wound infection and one wound dehiscence } \\
(9.5 \%)\end{array}$ \\
\hline Shehadi et al. [31] & $11.50 \%$ & $\begin{array}{l}\text { Median survival was } 21 \text { months, } 62 \% \text { at } 1 \text { year, } \\
33 \% \text { at } 3 \text { years, and } 24 \% \text { at } 5 \text { years }\end{array}$ & Major complications by surgical approach (17\%) \\
\hline Street et al. [19] & $2.30 \%$ & $75 \%$ at 6 months and $50 \%$ at 12 months & Major complications (26\%) \\
\hline
\end{tabular}

NA not available.

that of the MIS group (open: $88 \%$ versus MIS: $6.9 \%$ ). If there is truth that there is no significant difference in the functional outcome between the MIS and open group, the possible reason is that the potential benefit of MIS is counteracted by the more complicated nature of patients with metastatic spine disease during operation [33]. Payer et al. [34] also demonstrated that mean blood loss, operative time, and complication rates in spinal tumor patients were higher than that of the fracture patients with anterior approach.

\section{Conclusions}

In conclusion, we performed the systematic review based on literature published in the recent 10 years to possibly compare clinical efficiency and complication rate between open and MIS spinal surgery for spine metastasis and found that both open spinal surgery and MIS seem to achieve the improvement of pain and neurological dysfunction through decompression and stabilization, but open surgery may involve more major complications with a trend of lower survival rates and higher recurrence rates compared to MIS. However, it is necessary to perform a controlled study to compare the clinical efficiency between the two procedures for spine metastasis in the future.

\section{Competing interests}

The authors declare that they have no competing interests.

\section{Authors' contributions}

Study concept and design: $Y Z$ and $Y Y$. Searched references: $Y Y, Z Y, H L, Z Z$, $S Y, X D$, and $S H$. Manuscript preparation: $Y Y, Z Y, C Y$, and SY. Manuscript review: $Y Z$. The authors $Y Z, Y Y, Z Y, Z Z, C Y, S Y, H L, X D$, and $S H$ contributed equally to this work and should be considered as co-first authors. All authors have read and approval the final manuscript. 
Authors' information

Zuozhang Yang, Yihao Yang, Ya Zhang, Zhaoxin Zhang, Yanjin Chen, Yan Shen, Lei Han, Da Xu and Hongpu Sun were co-first authors.

\section{Acknowledgments}

This research was supported in part by grants (no. 81260322/H1606, no.81372322/H1606 and 81460440) from the National Natural Science Foundation of China, a grant (no. 2012FB163) from the Natural Science Foundation of Yunnan Province, a grant (no. 2014FB059) from the Joint Special Funds for the Department of Science and Technology of Yunnan Province-Kunming Medical University, and a grant (no. D-201242) from the specialty fund of high-level talents medical personnel training of Yunnan province.

Received: 6 July 2014 Accepted: 17 January 2015

\section{Published online: 21 February 2015}

\section{References}

1. Jemal A, Siegel R, Ward E, Hao Y, Xu J, Murray T, et al. Cancer statistics, 2008. CA Cancer J Clin. 2008:58(2):71-96.

2. Bartanusz V, Porchet F. Current strategies in the management of spinal metastatic disease. Swiss Surg. 2003;9(2):55-62

3. Sciubba DM, Gokaslan ZL, Suk I, Suki D, Maldaun MV, McCutcheon IE, et al. Positive and negative prognostic variables for patients undergoing spine surgery for metastatic breast disease. Eur Spine J. 2007;16(10):1659-67.

4. Moulding HD, Bilsky MH. Metastases to the craniovertebral junction. Neurosurgery. 2010;66(3):A113-A8.

5. Qureshi A, Shams U, Akhter A, Riaz S. Metastatic bone disease as seen in our clinical practice-experience at a tertiary care cancer center in Pakistan. Asian Pac J Cancer Prev. 2012;13(9):4369-71.

6. Ibrahim A, Crockard A, Antonietti P, Boriani S, Bünger C, Gasbarrini A, et al. Does spinal surgery improve the quality of life for those with extradural (spinal) osseous metastases? An international multicenter prospective observational study of 223 patients. J Neurosurg Spine. 2008;8(3):271-8.

7. Ryken TC, Eichholz KM, Gerszten PC, Welch WC, Gokaslan ZL, Resnick DK. Evidence-based review of the surgical management of vertebral column metastatic disease. Neurosurg Focus. 2003:15(5):1-10.

8. Coleman R. Metastatic bone disease: clinical features, pathophysiology and treatment strategies. Cancer Treat Rev. 2001;27(3):165-76.

9. Sciubba DM, Petteys RJ, Dekutoski MB, Fisher CG, Fehlings MG, Ondra SL, et al. Diagnosis and management of metastatic spine disease: a review. J Neurosurg Spine. 2010;13(1):94-108.

10. Harel R, Angelov L. Spine metastases: current treatments and future directions. Eur J Cancer. 2010;46(15):2696-707.

11. Klimo P, Schmidt MH. Surgical management of spinal metastases. Oncologist. 2004:9(2):188-96.

12. Lemke DM, Hacein-Bey L. Metastatic compression fractures-vertebroplasty for pain control. J Neurosci Nurs. 2003;35(1):50-5.

13. Brozek J, Akl E, Alonso-Coello P, Lang D, Jaeschke R, Williams J, et al. Grading quality of evidence and strength of recommendations in clinical practice guidelines. Allergy. 2009;64(5):669.

14. Schunemann HJ, Jaeschke R, Cook DJ, Bria WF, El-Solh AA, Ernst A, et al. An official ATS statement: grading the quality of evidence and strength of recommendations in ATS guidelines and recommendations. Am J Respir Crit Care Med. 2006;174(5):605-14.

15. Farrokhi M, Nouraei $\mathrm{H}$, Kiani A. The efficacy of percutaneous vertebroplasty in pain relief in patients with pathological vertebral fractures due to metastatic spinal tumors. Iran Red Crescent Med J. 2012;14(9):523.

16. Yang Z, Yang D, Xie L, Sun Y, Huang Y, Sun H, et al. Treatment of metastatic spinal tumors by percutaneous vertebroplasty versus percutaneous vertebroplasty combined with interstitial implantation of 1251 seeds. Acta Radiol. 2009;50(10):1142-8.

17. Pflugmacher R, Taylor R, Agarwal A, Melcher I, Disch A, Haas N, et al. Balloon kyphoplasty in the treatment of metastatic disease of the spine: a 2-year prospective evaluation. Eur Spine J. 2008;17(8):1042-8.

18. Anselmetti GC, Manca A, Tutton S, Chiara G, Kelekis A, Facchini FR, et al. Percutaneous vertebral augmentation assisted by PEEK implant in painful osteolytic vertebral metastasis involving the vertebral wall: experience on 40 patients. Pain Physician. 2013;16:E397-404.

19. Street J, Fisher C, Sparkes J, Boyd M, Kwon B, Paquette S, et al. Single-stage posterolateral vertebrectomy for the management of metastatic disease of the thoracic and lumbar spine: a prospective study of an evolving surgical technique. J Spinal Disord Tech. 2007;20(7):509-20.

20. Pizzoli AL, Brivio LR, Caudana R, Vittorini E. Percutaneous CT-guided vertebroplasty in the management of osteoporotic fractures and dorsolumbar metastases. Orthop Clin N Am. 2009;40(4):449-58.

21. Chen $\mathrm{K}-\mathrm{Y}, \mathrm{Ma} \mathrm{H}-\mathrm{I}$, Chiang $\mathrm{Y}-\mathrm{H}$. Percutaneous transpedicular vertebroplasty with polymethyl methacrylate for pathological fracture of the spine. J Clin Neurosci. 2009;16(10):1300-4.

22. Qian Z, Sun Z, Yang H, Gu Y, Chen K, Wu G. Kyphoplasty for the treatment of malignant vertebral compression fractures caused by metastases. J Clin Neurosci. 2011;18(6):763-7.

23. Tseng $Y-Y$, Lo $Y$-L, Chen L-H, Lai P-L, Yang S-T. Percutaneous polymethylmethacrylate vertebroplasty in the treatment of pain induced by metastatic spine tumor. Surg Neurol. 2008;70:S78-83.

24. Holman PJ, Suki D, McCutcheon I, Wolinsky J-P, Rhines LD, Gokaslan ZL. Surgical management of metastatic disease of the lumbar spine: experience with 139 patients. J Neurosurg Spine. 2005;2(5):550-63.

25. Chong S, Shin S-H, Yoo H, Lee SH, Kim K-J, Jahng T-A, et al. Single-stage posterior decompression and stabilization for metastasis of the thoracic spine: prognostic factors for functional outcome and patients' survival. The Spine Journal. 2012;12(12):1083-92.

26. Eid AS, Chang U-K. Anterior construct location following vertebral body metastasis reconstruction through a posterolateral transpedicular approach: does it matter? Clin Art J Neurosurg Spine. 2011;14(6):734-41.

27. Liang $T$, Wan $Y$, Zou X, Peng X, Liu S. Is surgery for spine metastasis reasonable in patients older than 60 years? Clinical Orthopaedics and Related Research ${ }^{\circledast}$. 2013;471(2):628-39.

28. Cho W, Chang U-K. Neurological and survival outcomes after surgical management of subaxial cervical spine metastases. Spine. 2012;37(16):E969-E77.

29. Walter J, Reichart R, Waschke A, Kalff R, Ewald C. Palliative considerations in the surgical treatment of spinal metastases. J Cancer Res Clin Oncol. 2012;138(2):301-10.

30. Cho D-C, Sung J-K. Palliative surgery for metastatic thoracic and lumbar tumors using posterolateral transpedicular approach with posterior instrumentation. Surg Neurol. 2009;71(4):424-33.

31. Shehadi JA, Sciubba DM, Suk I, Suki D, Maldaun MV, McCutcheon IE, et al. Surgical treatment strategies and outcome in patients with breast cancer metastatic to the spine: a review of 87 patients. Eur Spine J. 2007;16(8):1179-92.

32. Huang T-J, Hsu RW-W, Li Y-Y, Cheng C-C. Minimal access spinal surgery (MASS) in treating thoracic spine metastasis. Spine. 2006;31(16):1860-3.

33. Huang TJ, Hsu RW, Sum CW, Liu HP. Complications in thoracoscopic spinal surgery: a study of 90 consecutive patients. Surg Endosc. 1999;13(4):346-50.

34. Payer M, Sottas C. Mini-open anterior approach for corpectomy in the thoracolumbar spine. Surg Neurol. 2008;69(1):25-31.

\section{Submit your next manuscript to BioMed Central and take full advantage of:}

- Convenient online submission

- Thorough peer review

- No space constraints or color figure charges

- Immediate publication on acceptance

- Inclusion in PubMed, CAS, Scopus and Google Scholar

- Research which is freely available for redistribution 